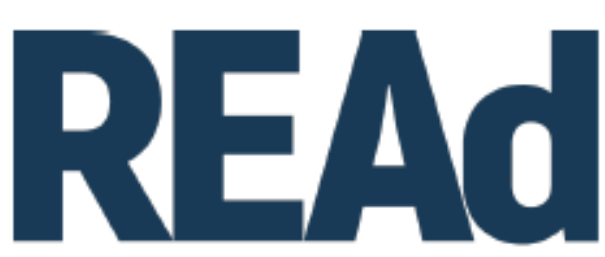

Revista Eletrônica de Administração

\title{
ALÉM DAS EQUIPES INTERGERACIONAIS: POSSIBILIDADES DE ESTUDOS SOBRE AGEISMO ${ }^{1}$
}

\author{
Thales Fabrício da Costa e Silva ${ }^{2}$ \\ Débora Bruna Alves Almeida ${ }^{3}$ \\ Eduardo de Camargo Oliva ${ }^{4}$ \\ Edson Keyso de Miranda Kubo ${ }^{5}$
}

http://dx.doi.org/10.1590/1413-2311.327.101822

\section{RESUMO}

O trabalho tem o objetivo de articular, por meio de um ensaio teórico, contribuições de pesquisas sobre o ageismo envolvendo as principais estratégias de enfrentamento no contexto organizacional, refletindo criticamente sobre a prevalência que é dada à formação de equipes intergeracionais nas organizações. Verifica-se um número maior de estudos baseados em discussões teóricas e poucas pesquisas empíricas acerca do tema. Como resultados, observa-se que, embora seja comum a propositura da formação de equipes intergeracionais nos espaços de trabalho como estratégia de mitigação do ageismo, faz-se necessária a implementação concomitante de outras estratégias que envolvam a inclusão e permanência de trabalhadores mais velhos. Essas estratégias consistem em políticas de contratação desses trabalhadores, qualificação profissional, flexibilização das condições de trabalho, sensibilização e conscientização dos trabalhadores mais jovens, gerenciamento de equipes intergeracionais e aproveitamento de mão de obra qualificada. Este ensaio contribui para a teoria e a prática organizacional, pois problematiza o conceito de gerações caracterizadas pela idade cronológica, reforça a heterogeneidade da força de trabalho e incentiva a discussão sobre o tema e sobre potenciais práticas de mitigação do ageismo no seio das organizações.

\footnotetext{
${ }^{1}$ Recebido em 9/4/2020, aceito em 12/3/2021.

${ }^{2}$ Universidade Municipal de São Caetano do Sul - Programa de Pós-Graduação em Administração; São Caetano do Sul - SP (Brasil); https://orcid.org/0000-0003-1828-3259; thalespsic@ gmail.com.

${ }^{3}$ Universidade Municipal de São Caetano do Sul - Programa de Pós-Graduação em Administração; São Caetano do Sul - SP (Brasil); https://orcid.org/0000-0002-9758-3227; deborabruna20@ yahoo.com.br.

${ }^{4}$ Universidade Municipal de São Caetano do Sul - Programa de Pós-Graduação em Administração; São Caetano do Sul - SP (Brasil); https://orcid.org/0000-0002-7454-3759; ec.oliva@ terra.com.br.

${ }^{5}$ Universidade Municipal de São Caetano do Sul - Programa de Pós-Graduação em Administração; São Caetano do Sul - SP (Brasil); https://orcid.org/0000-0001-9017-2487; edson.kubo@ prof.uscs.edu.br.
} 
Palavras-chave: Ageismo. Gerações. Envelhecimento. Relações de trabalho.

\section{BEYOND INTERGERATIONAL TEAMS: POSSIBILITIES OF STUDIES ON AGEISM}

The work aims to articulate, through a theoretical essay, researchs contributions on ageism involving the main coping strategies in the organizational context, reflecting critically on the prevalence that is given to the formation of intergenerational teams in organizations. There is a greater number of studies based on theoretical discussions and little empirical research on the theme. As a result, it is observed that, although it is common to propose the formation of intergenerational teams in the workspaces as a strategy to mitigate ageism, it is necessary to implement simultaneously other strategies that involve the inclusion and permanence of older workers. These strategies consist of policies for hiring these workers, professional qualification, flexibility in working conditions, sensitization and awareness of younger workers, management of intergenerational teams and use of qualified labor. This essay contributes to organizational theory and practice, as it problematizes the concept of generations characterized by chronological age, reinforces the heterogeneity of the workforce and encourages discussion on the topic and on potential practices for mitigating ageism within organizations.

Keywords: Ageism. Generations. Aging. Work relationships.

\section{MÁS ALLÁ DE LOS EQUIPOS INTERGERACIONALES: POSIBILIDADES DE ESTUDIOS SOBRE AGEISMO}

El trabajo tiene como objetivo articular, a través de un ensayo teórico, contribuciones de investigaciónes sobre el ageismo involucrando las principales estrategias de afrontamiento en el contexto organizacional, reflexionando críticamente sobre la prevalencia que se da a la formación de equipos intergeneracionales en las organizaciones. Hay un mayor número de estudios basados en discusiones teóricas y poca investigación empírica sobre el tema. Como resultado, se observa que, si bien es común la proposicion de la formación de equipos intergeneracionales en los espacios de trabajo como estrategia para mitigar la discriminación por edad, es necesario implementar simultáneamente otras estrategias que involucren la inclusión y permanencia de los trabajadores mayores. Estas estrategias consisten en políticas de contratación de estos trabajadores, calificación profesional, flexibilización en las condiciones laborales, sensibilización y concientización de los trabajadores más jóvenes, gestión de equipos intergeneracionales y uso de mano de obra calificada. Este ensayo contribuye a la teoría y práctica organizacional, ya que problematiza el concepto de generaciones caracterizadas por la edad cronológica, refuerza la heterogeneidad de la fuerza laboral y fomenta la discusión sobre el tema y las prácticas potenciales para mitigar el ageismo dentro de las organizaciones.

Palabras clave: Ageism. Generaciones. Envejecimiento. Relaciones de trabajo. 


\section{INTRODUÇÃO}

Segundo as projeções do IBGE (2018), com o crescimento da população desacelerando, o país apresentará seu ápice populacional no ano de 2047, período em que a esperança de vida ao nascer girará em torno de 80 anos, a taxa de fecundidade atingirá 1,68 e haverá uma alta concentração populacional entre homens e mulheres de 45 a 64 anos de idade. Essas mudanças no contexto demográfico brasileiro requisitam atenção especial para uma das principais características deste novo cenário: o envelhecimento da força de trabalho.

Entre os estudos nacionais e internacionais sobre as gerações e o mercado de trabalho, destaca-se o fenômeno ageismo, conceito cunhado por Butler (1969) para caracterizar o preconceito relacionado à idade; embora o termo se refira ao preconceito sobre qualquer idade, a repulsa gerada pelo simbolismo inerente ao processo de envelhecimento (envelhecer como sinônimo de se tornar "impotente", "incapaz" ou "inútil”) fez com que o termo ageismo - e seus correlatos: idadismo e etarismo - fosse direcionado ao público mais velho.

Neste cenário, discute-se a valorização da intergeracionalidade no ambiente de trabalho como uma das maneiras de mitigar atitudes ageistas. Alguns pesquisadores sobre o tema (SILVA; HELAL, 2019; FRANÇA et al., 2017; SILVA et al., 2014; FONTOURA; PICCININI, 2012) apontam para a inserção e permanência de trabalhadores de várias idades nos postos de trabalho como estratégia de enfrentamento a esse tipo de preconceito. Porém, frente aos inúmeros desdobramentos da prática ageista no contexto organizacional, alguns estudos sugerem que apenas a formação de equipes intergeracionais não seja suficiente para combater o preconceito etário (FRANÇA et al., 2017; IWEINS et al., 2013; IWEINS; DESMETTE; YZERBYT, 2012).

Portanto, este artigo tem o objetivo de reunir contribuições de pesquisas sobre o ageismo envolvendo as principais estratégias de enfrentamento no contexto organizacional, refletindo criticamente sobre a prevalência que é dada à formação de equipes intergeracionais nas organizações.

Defende-se que a mitigação do ageismo nas organizações deve ocorrer através da adoção de estratégias que vão além da formação de equipes intergeracionais, incluindo, paralelamente, outras ações de inserção e permanência de trabalhadores nas diversas faixas etárias, sobretudo os mais velhos (que majoritariamente sofrem preconceito etário), como políticas de contratação desses trabalhadores, qualificação profissional, flexibilização das condições de trabalho, sensibilização e conscientização dos trabalhadores mais jovens acerca 
dos estereótipos etários, gerenciamento das equipes intergeracionais e aproveitamento de mão de obra qualificada.

Este ensaio apresenta relevância ao expor estudos nacionais e internacionais que revelam as principais implicações da prática ageista no contexto organizacional e discutem a relação intergeracional propagada no seio das organizações como a estratégia de enfrentamento ao ageismo mais citada pelos estudiosos, mas que poderia ser acompanhada de outras iniciativas que são abordadas ao longo deste trabalho.

\section{ENVELHECIMENTO E PRECONCEITO ETÁRIO}

As transformações tecnológicas, econômicas, culturais e sociais influenciam sobremaneira o conceito de envelhecimento na atualidade. Soma-se a isso, a dificuldade histórica de demarcar um conceito robusto e definitivo sobre o que é envelhecer.

Por muito tempo, buscou-se definir o envelhecimento a partir de uma perspectiva biológica e, consequentemente, marcada pela idade cronológica. Porém, como aponta Groisman (2002), esse critério é falho e arbitrário, já que o envelhecimento é vivenciado de forma heterogênea pela população, visto que pessoas da mesma idade cronológica podem estar em estágios do envelhecimento (do ponto de vista orgânico) completamente distintos.

No campo da Psicologia, uma teoria bastante reconhecida é a perspectiva lifespan de envelhecimento, desenvolvida por Baltes (1987), que consiste na ideia de desenvolvimento ao longo de toda a vida; assim, o desenvolvimento/envelhecimento é um processo contínuo, multidimensional e multidirecional de mudanças influenciadas por questões genéticobiológicas e socioculturais de natureza normativa e não-normativa, marcado por ganhos e perdas concorrentes e por interatividade indivíduo-cultura e entre os níveis e tempos das influências (NERI, 2006).

Ante o exposto, este trabalho se assenta no conceito de envelhecimento lifespan, também defendido por Loth e Silveira (2014), para os quais a velhice não pode ser reduzida a um evento único (cronológico), que desconsidera variáveis como a história, a cultura e o lugar; assim, o sujeito envelhecente é observado pela perspectiva de curso de vida que busca descronologizar a velhice e o envelhecimento. Por essa perspectiva, o conceito de velhice tem elementos biológicos, psicológicos e socioculturais que se interseccionam com outras dimensões sociais, como gênero, classe social e o período histórico. Assim, Schneider e Irigaray (2008) afirmam que as condições históricas, políticas, econômicas, geográficas e culturais 
produzem diferentes representações sociais da velhice e estas, por sua vez, influenciam as atitudes individuais e/ou coletivas frente as pessoas que estão envelhecendo.

As teorias construídas acerca do fenômeno envelhecimento contribuem para a construção de estereótipos. Como afirmam Teixeira, Souza e Maia (2018), estereótipos não são apenas formas simplistas de descrever um grupo, mas estruturas cognitivas que permeiam os modos de pensar e se comportar dos indivíduos, podendo ser positivos, negativos ou neutros. Vieira e Lima (2015) apontam que as diversas teorias e pesquisas internacionais e nacionais sobre o envelhecimento têm oportunizado estereotipias ambivalentes sobre as pessoas mais velhas: as negativas compreendem concepções relacionadas a declínio, perdas, doença, inutilidade, isolamento, fragilidade, pobreza, entre outras, e as positivas dizem respeito, entre outras, à gentileza, experiência, sabedoria, confiança, liberdade e juventude prolongada.

Cabe considerar que os estereótipos sobre a velhice, em sua grande maioria, estão vinculados à idade cronológica como fator determinante e, como defende Goldani (2010), agir a partir de estereótipos baseados na idade é claramente preconceituoso. Butler (1980) afirmou que o processo de estereotipar e discriminar pessoas em virtude da idade apresenta impacto em três grandes áreas: preconceito social, sistema de saúde e locais de trabalho. Demarcando uma das principais contribuições sobre o tema, Butler $(1969,1980)$ considera que o ageismo pode ocorrer paralelamente com outros tipos de preconceito, como o racismo e sexismo, porém, diferente destes, o ageismo pode acometer qualquer indivíduo. No contexto do trabalho, o autor apontava exemplos da prática ageista: aposentadoria compulsória, dificuldades promocionais e o fator idade nas contratações como elemento superior à competência individual.

\section{IMPLICAÇÕES DA PRÁtiCA AGEISTA PARA O CONTEXTO ORGANIZACIONAL}

Identifica-se que uma das principais lacunas nos estudos organizacionais sobre envelhecimento da força de trabalho no Brasil diz respeito ao número reduzido de pesquisas sobre o ageismo. A ampliação dos estudos sobre o tema é importante porque o preconceito em virtude da idade, embora possa ser facilmente identificado em alguns contextos, geralmente é manifestado de forma encoberta e sutil, podendo tornar o seu enfrentamento mais desafiador (TEIXEIRA; SOUZA; MAIA, 2018; BOURRY; OLIVEIRA, 2017; NELSON, 2011).

Helal e Silva (2019) escrevem que o ageismo organizacional é o conjunto de atitudes negativas ou positivas frente ao processo do envelhecer, que perpassa a valorização ou 
desvalorização para com a força do trabalho dos mais velhos, e pode favorecer ou desfavorecer esses sujeitos, influenciando desde a contratação até a dispensa.

Mesmo havendo estereótipos positivos e negativos sobre as pessoas mais velhas, há uma sobreposição desses últimos, trazendo consequências negativas ao bem-estar dos indivíduos, deturpando sua autoimagem, senso de autoeficácia e a motivação para viver a velhice (TEIXEIRA; SOUZA; MAIA, 2018).

No contexto organizacional, uma das principais consequências do ageismo para o indivíduo é a sua contínua expulsão do mercado, dado que o processo de estereotipar e discriminar o sujeito em função da sua idade influencia a sua contratação, inserção e permanência no mercado (AQUINO, 2018; BOURRY; OLIVEIRA, 2017; FRANÇA et al., 2017; PERES, 2003). Como aponta Paolini (2016), esse processo é potencializado pela valorização do jovem para a economia em detrimento do idoso, que é visto como alguém que se aproxima do final do ciclo produtivo por causa da idade.

Além disso, há consequências relacionadas ao desempenho de tarefas no trabalho. McGregor e Gray (2002), ao pesquisar sobre estereótipos em trabalhadores mais velhos, identificaram que, devido ao rótulo de pouco adaptáveis e resistentes a mudanças, alguns profissionais idosos eram vistos como incompetentes para novos aprendizados e, por isso, eram excluídos de novos treinamentos. Nesse caso, privá-los de treinamentos poderia resultar em dificuldades para acompanhar as mudanças e se adaptarem no ambiente de trabalho, reforçando o estereótipo. Em outras palavras, como apontam Loth e Silveira (2014), as empresas investem seus recursos nos mais novos, não possibilitando a mesma oportunidade aos mais velhos que, por sua vez, acabam sendo percebidos como menos propícios ao treinamento (estereótipos), formando um ciclo vicioso das ações organizacionais dirigidas aos mais velhos.

Outra consequência do ageismo identificada nos indivíduos é a perda da identificação positiva que o indivíduo possui com o trabalho, influenciando significativamente na sua satisfação (LEVY; MACDONALD, 2016). Nesse sentido, compreendendo que a satisfação no trabalho é resultante de uma complexa interação entre fatores como relações interpessoais e os processos de trabalho, estar insatisfeito pode gerar prejuízos à saúde mental e à capacidade para o trabalho, acarretando efeitos negativos ao indivíduo e à própria organização, como absenteísmo, rotatividade, queda na produtividade e atrasos ou pausas prolongadas e/ou não autorizadas (MARQUEZE; MORENO, 2005; MARTINEZ; PARAGUAY; LATORRE, 2004). Esses efeitos podem ser potencializados pelo desinteresse nas relações entre gerações e na execução das atividades laborais provocados pelo ageismo, conforme apontam Paiva, Sobreira e Lima (2019). 
Nelson (2011), ao discutir o ageismo na sociedade americana, aponta que o fenômeno está fortemente ligado à ênfase que é colocada pela cultura local na mudança, mobilidade e velocidade na vida dos trabalhadores; assim, quanto maior essa ênfase, mais provável será a sociedade perceber o trabalhador mais velho como não competitivo e considerá-lo um fardo sobre os recursos da sociedade. Neste sentido, ele ressalta que uma das principais consequências do ageismo ao trabalhador é a perda da identidade desse sujeito em virtude da sua ausência do mundo do trabalho.

Outra contribuição é apresentada por Clark e Ogawa (1996) quando apontam a reorganização no mundo do trabalho ocorrida no Japão (tanto em nível organizacional quanto governamental), ainda na década de 1980, frente ao envelhecimento da força de trabalho à época. Com o objetivo de delongar a vida laboral, o governo japonês prolongou o prazo para aposentadoria compulsória, alterou o sistema de remuneração e pôs fim ao emprego vitalício. Como efeitos de tais mudanças, os trabalhadores passaram a viver com mais incertezas sobre estabilidade financeira e de carreira, maior insatisfação dos trabalhadores com os empregadores e maior índice de turnover entre trabalhadores mais experientes.

Para Fontoura e Piccinini (2012, p. 14), com o envelhecimento da força de trabalho em todo o mundo, "não basta discutir ações que visem manter o trabalhador que envelhece no mercado de trabalho ou fazer com que retorne se no dia a dia de trabalho não the forem oferecidas condições de trabalho saudáveis e decentes”. Para Malatest (2003), essas condições do ambiente de trabalho incluem a mudança de atitudes no interior das organizações e constituem um dos desafios para a área de gestão de pessoas. Portanto, se más condições de trabalho podem funcionar como preditores para uma aposentadoria precoce em virtude dos prejuízos à saúde do trabalhador e insatisfação com o trabalho, como apontam Keel, Sauter e Hanseman (2009), é possível pensar que as organizações que não adotam estratégias de combate ao ageismo, podem ser consideradas como organizações que não oferecem condições de trabalho adequadas aos seus trabalhadores.

Como é possível observar, o ageismo no ambiente organizacional também se origina dos estereótipos atribuídos à idade cronológica e incidem sobre a vida do trabalhador e da própria organização, afetando as relações interpessoais, os processos de trabalho, a saúde do trabalhador e outros elementos organizacionais. O seu enfrentamento é necessário, especialmente ao constatar o envelhecimento da força de trabalho em vários países, como o Brasil. Para tanto, uma das alternativas bastante disseminadas é o desenvolvimento de equipes intergeracionais, o que preconiza a relação de trabalhadores das diversas gerações no interior 
das organizações. Desse modo, faz-se necessário discutir sobre as gerações e como é possível fomentar as relações intergeracionais no ambiente de trabalho.

\section{RELAÇÕES INTERGERACIONAIS NO AMBIENTE DE TRABALHO}

Nos estudos sobre o ageismo nas organizações, vários elementos atravessam a temática, como as modificações no(s) conceito(s) de envelhecimento, a influência de elementos organizacionais (a exemplo da cultura e clima organizacionais), as possíveis causas e consequências do ageismo e as estratégias organizacionais para a gestão dessa prática; entre essas estratégias, a formação de equipes intergeracionais é uma das mais citadas. Gonçalves e Ferreira (2016), ao abordarem as diferenças e semelhanças entre as gerações no contexto organizacional, apontam para o incentivo da relação intergeracional entre os trabalhadores das gerações Baby Boomer, X, Y e Z. Segundo os autores, os trabalhadores da geração Baby Boomer (nascidos entre 1946 e 1964) são otimistas, focados, automotivados, comprometidos e fiéis à empresa e às políticas organizacionais. A geração X (nascidos entre 1960 e 1980) é composta por profissionais mais racionais, individualistas, competitivos, com foco em resultados e maior habilidade de trabalhar sob pressão. Os trabalhadores da geração Y (nascidos entre as décadas de 1980 e 1990) conseguem utilizar com facilidade as tecnologias, têm necessidade de receber constantes feedbacks, gostam de inovação, possuem foco em resultados e priorizam liberdade no trabalho. Por fim, a geração Z (nascidos após a década de 2000) é formada por trabalhadores inquietos, que nasceram imersos na tecnologia e na velocidade do conhecimento, pouco fiéis às marcas e com grande habilidade de realizar tarefas plurais.

Gonçalves e Ferreira (2016) ainda apontam que o compartilhamento das informações entre as gerações pode auxiliar os processos de trabalho e situações da vida pessoal. Para os autores, considerando a presença de trabalhadores de várias gerações no mesmo espaço de trabalho, é preciso valorizar o que cada geração tem de melhor, minimizando os conflitos entre elas. Como apontam Becton, Walker e Jones-Farmer (2014), o não reconhecimento dessas diferenças por parte da organização pode conduzir a resultados organizacionais negativos, como conflitos entre as gerações, falhas de comunicação, relações de trabalho negativas, redução da produtividade e do bem-estar dos trabalhadores, e menor cidadania organizacional. Nesse sentido, o desenvolvimento de equipes intergeracionais tem sido incentivado por alguns estudiosos (CEPELLOS; TONELLI, 2017; FRANÇA et al., 2017; HELAL; NÓBREGA; LIMA, 2017; GONÇALVES; FERREIRA, 2016; SILVA et al., 2014; LIMA; HELAL, 2013; 
CEPELLOS, 2013), pois pode contribuir para a valorização da relação e redução dos conflitos entre os trabalhadores das diversas gerações.

Apesar da classificação das gerações Baby Boomer, X, Y e Z ser amplamente utilizada na literatura internacional, atualmente, debate-se acerca da aplicabilidade dessa classificação para o cenário nacional, uma vez que, de acordo com Milhome e Rowe (2020), é inadequada a importação da classificação geracional de outro país, visto que o contexto social e histórico são marcadores fundamentais da construção das gerações em cada sociedade.

No caso brasileiro, Milhome e Rowe (2020) propõem uma classificação geracional dividida em sete cortes - Geração nacionalista (nascidos entre os anos 1910 a 1929), Geração pré-ditadura (1930 a 1943), Geração reprimida (1944 a 1958), Geração diretas (1959 a 1968), Geração hiperinflação (1969 a 1978), Geração social (1979 a 1991) e Geração 4.0 (1992 a 2004) - o que pode influenciar os estudos sobre gerações e mercado de trabalho no Brasil. Ainda não foram identificados estudos que descrevam as características dos trabalhadores dessas gerações no mercado de trabalho brasileiro.

Apesar da importância dos estudos sobre gerações no ambiente organizacional, é fundamental que as organizações estejam atentas, sobretudo, às características e às demandas dos seus trabalhadores para além de um recorte geracional, considerando a heterogeneidade inerente à força de trabalho. Um exemplo disso diz respeito à criatividade no trabalho, que comumente é atribuída aos trabalhadores mais novos (DRUMOND et al., 2020; GONÇALVES; FERREIRA, 2016), mas como pontuam Gomes, Rodrigues e Veloso (2016), a criatividade é um processo complexo e multifacetado, que se desenvolve em torno da esfera pessoal, social e cultural em que o indivíduo está inserido, não sendo possível definir um perfil criativo simplesmente a partir da idade cronológica.

Frente ao exposto, a formação das equipes intergeracionais deve ser considerada no contexto organizacional como uma estratégia de mitigação do ageismo, porém, defende-se que a formação dessas equipes não deve ser meramente baseada em classificação geracional, mas considerando também a diversidade que demarca a força de trabalho, como outras características sociodemográficas, experiências profissionais, competências, conhecimentos, atributos comportamentais, entre outros aspectos.

Outrossim, como apontam Iweins, Desmette e Yzerbyt (2012), embora alcançar a diversidade etária no trabalho possa ser um objetivo sensato e desejável, o método usado para atingir esse objetivo também pode desencadear o aumento do ageismo. Portanto, Iweins et al. (2013) também reforçam que a formação de equipes intergeracionais deve ser acompanhada de estratégias eficazes para promover maior diversidade e tolerância nos espaços de trabalho. 
Nesse sentido, França et al. (2017) afirmam que as organizações precisam promover saúde, segurança e qualidade do ambiente para os mais velhos continuarem trabalhando, e Carvalho (2009) assevera sobre a criação de um ambiente organizacional saudável, no qual a autoestima seja elevada independentemente da idade do trabalhador, valorizando suas habilidades e competências.

O fomento à formação e às relações de equipes intergeracionais é visto como um dos pilares do enfrentamento ao ageismo nas organizações (CEPELLOS; TONELLI, 2017; FRANÇA et al., 2017; HELAL; NÓBREGA; LIMA, 2017; GONÇALVES; FERREIRA, 2016; SILVA et al., 2014; LIMA; HELAL, 2013; CEPELLOS, 2013), que pode ser acompanhado de outras ações no âmbito organizacional. Em estudos nacionais que abordam a atuação das organizações no enfrentamento ao ageismo, os autores apontam algumas possibilidades: oferecer condições de trabalho saudáveis e decentes aos trabalhadores mais velhos, (re)inserção e manutenção de pessoas mais velhas nos postos de trabalho formal e promoção de treinamentos e qualificação adequados para esse grupo geracional (FONTOURA e PICCININI, 2012), orientar o comportamento humano no trabalho com vistas a diminuir os efeitos das diferenças etárias (PAIVA; SOBREIRA; LIMA, 2019; SILVA et al., 2014), criar mais oportunidades para trabalhadores mais velhos (HELAL; NÓBREGA; LIMA, 2017), políticas públicas e políticas de Recursos Humanos (RH) voltadas ao enfrentamento do preconceito de idade (BOURRY; OLIVEIRA, 2017; VASCONCELOS, 2012), conscientizar os trabalhadores acerca da importância de partilhar o ambiente de trabalho com profissionais mais velhos (CEPELLOS; TONELLI, 2017), flexibilização de algumas ações ao público idoso, como redução da jornada de trabalho e adequação de atividades frente às transformações físicas (AQUINO, 2018; FRANÇA et al., 2017) e reconhecer direitos e proporcionar oportunidades a todos os trabalhadores, alcançando um ambiente de trabalho com equidade (SILVA; HELAL, 2019).

Os estudos que apresentam ações de mitigação do ageismo nas organizações, seja a partir de práticas já implementadas ou de discussões que sugerem práticas possíveis, foram sistematizados no Quadro 1.

Quadro 1 - Possibilidades de mitigação do ageismo nas organizações

\begin{tabular}{|c|l|}
\hline Obra & Estratégias elencadas pelos autores \\
\hline $\begin{array}{c}\text { Fontoura e Piccinini } \\
\text { (2012) }\end{array}$ & $\begin{array}{l}\text { Garantir a (re)inserção e manutenção de pessoas mais velhas em postos de trabalho } \\
\text { formais; } \\
\text { Proporcionar formas de treinamentos e qualificação profissional que sejam adequadas } \\
\text { aos mais velhos. }\end{array}$ \\
\hline Vasconcelos (2012) & $\begin{array}{l}\text { Conscientização dos tomadores de decisão e do monitoramento contínuo da idade e } \\
\text { dos valores mantidos pelos gerentes, a diversidade demográfica organizacional, os } \\
\text { grupos-alvo de treinamento, oportunidades de contratação e promoção, declarações } \\
\text { de missão, valores organizacionais e legislação. }\end{array}$ \\
\hline
\end{tabular}




\begin{tabular}{|c|c|}
\hline Cepellos (2013) & $\begin{array}{l}\text { Conscientizar os membros da empresa com relação à importância de se trabalhar com } \\
\text { profissionais mais velhos; } \\
\text { Especificar as atividades de trabalho de acordo com a capacidade do profissional; } \\
\text { Realizar atividades de trabalho entre membros de diferentes idades; } \\
\text { Selecionar candidatos de diferentes idades. }\end{array}$ \\
\hline Lima e Helal (2013) & Valorização do trabalho na terceira idade e dos relacionamentos intergeracionais. \\
\hline Silva et al. (2014) & $\begin{array}{l}\text { Fomentar a interação entre os empregados de distintas faixas etárias, estimulando a } \\
\text { troca de conhecimentos e experiências; } \\
\text { Orientar o comportamento humano em coerência com o modelo de gestão } \\
\text { organizacional, mitigando os efeitos das diferenças geracionais baseadas em idade. }\end{array}$ \\
\hline $\begin{array}{l}\text { Gonçalves e Ferreira } \\
(2016) \\
\end{array}$ & $\begin{array}{l}\text { Incentivar as relações entre as gerações no ambiente de trabalho, valorizando o que } \\
\text { cada uma tem de melhor, minimizando os conflitos entre elas. }\end{array}$ \\
\hline $\begin{array}{l}\text { Bourry e Oliveira } \\
\qquad(2017)\end{array}$ & $\begin{array}{l}\text { Criar políticas públicas voltadas ao enfrentamento do ageismo; } \\
\text { Repensar, no âmbito das organizações brasileiras, as políticas de } \mathrm{RH} \text {, de forma a criar } \\
\text { mecanismos para absorver melhor e mais prontamente as pessoas na maturidade. }\end{array}$ \\
\hline França et al. (2017) & $\begin{array}{l}\text { Criar programas de incentivo que visem à retenção de mão de obra especializada de } \\
\text { trabalhadores mais velhos por meio de redução e/ou flexibilização da carga horária, } \\
\text { de licenças especiais e da carga de trabalho. }\end{array}$ \\
\hline $\begin{array}{l}\text { Helal, Nóbrega e } \\
\text { Lima (2017) }\end{array}$ & $\begin{array}{l}\text { Criar mais oportunidades para trabalhadores mais velhos no mercado de trabalho; } \\
\text { Implementar programas que contemplem espaços de aprendizagem e de } \\
\text { compartilhamento de experiências profissionais entre gerações de trabalhadores. }\end{array}$ \\
\hline Aquino (2018) & $\begin{array}{l}\text { Possibilitar práticas em que os trabalhadores idosos sejam colocados em evidência de } \\
\text { maneira positiva, a fim de estreitar os laços e as trocas intergeracionais; } \\
\text { Desmistificar os estereótipos negativos acerca do idoso através de ações e políticas } \\
\text { como: jornada reduzida de trabalho, adequação de atividades às transformações } \\
\text { físicas da idade quando necessário e manutenção do idoso em programas de } \\
\text { capacitação. }\end{array}$ \\
\hline $\begin{array}{l}\text { Paiva, Sobreira e } \\
\text { Lima (2019) }\end{array}$ & $\begin{array}{l}\text { Instigar a mudança de comportamento, rumo à abolição de estereótipos e } \\
\text { discriminações. }\end{array}$ \\
\hline Silva e Helal (2019) & $\begin{array}{l}\text { Conciliar direitos e oportunidades para todos os trabalhadores, independentemente de } \\
\text { sua idade, proporcionando um ambiente de trabalho com equidade; } \\
\text { Utilizar práticas como psicoeducação para conscientizar os membros das } \\
\text { organizações acerca da importância de se trabalhar com profissionais mais velhos, } \\
\text { além de montar equipes com membros de diferentes idades e possibilitar a seleção de } \\
\text { candidatos de diferentes idades. }\end{array}$ \\
\hline
\end{tabular}

É importante considerar que, dos estudos citados, somente os de Bourry e Oliveira (2017), França et al. (2017) e Cepellos (2013) são frutos de pesquisa empírica, os demais são provenientes de discussões conceituais e bibliográficas. Das pesquisas aplicadas, apenas a de Cepellos (2013) advém de investigação com gestores em atuação (neste caso, gestores de RH), que são atores fundamentais para o funcionamento organizacional. Neste estudo, foram investigadas as percepções de gestores de $\mathrm{RH}$ a respeito dos profissionais com mais de 50 anos e as práticas de gestão de idade adotadas nas suas empresas. Os resultados apontaram que, ainda que a percepção dos gestores acerca dos profissionais mais velhos seja relativamente positiva, práticas de gestão de idade são incomuns nas suas empresas, mostrando que o discurso muitas vezes é contraditório com as ações organizacionais e que essas organizações não estão preparadas para o envelhecimento da força de trabalho. Tal informação mantém a inquietação a respeito da formação de equipes intergeracionais nas organizações: se a formação de equipes 
intergeracionais é um discurso e uma prática efetivamente adotada pelos gestores nas organizações.

Nota-se, pelo Quadro 1, que as estratégias de enfrentamento ao ageismo apontadas nas pesquisas nacionais englobam tanto iniciativas governamentais - quando se referem à elaboração de políticas públicas direcionadas aos trabalhadores mais velhos - quanto das próprias organizações, quando citam a elaboração de políticas organizacionais e de práticas de RH que estimulem a equidade entre seus trabalhadores.

É importante destacar que a sugestão de políticas públicas para trabalhadores mais velhos surge de forma superficial entre os estudos nacionais, não havendo orientações específicas aos elaboradores e implementadores de políticas públicas no Brasil. Já quanto às políticas e práticas organizacionais, são elencadas, de modo geral, ações tanto de inserção (políticas de contratação de trabalhadores nas diversas faixas etárias) quanto de permanência de trabalhadores mais velhos nos espaços de trabalho (qualificação profissional, flexibilização das condições de trabalho, sensibilização e conscientização dos trabalhadores mais jovens, gerenciamento de equipes intergeracionais e aproveitamento de mão de obra qualificada).

Essas proposituras constituem alternativas organizacionais concomitantes à constituição das equipes intergeracionais, pois, como debatido neste ensaio, apenas a formação de equipes com trabalhadores de várias gerações pode não ser suficiente para mitigar o ageismo se essas equipes não forem amparadas por outras políticas e práticas de $\mathrm{RH}$, como espaços de socialização intergeracional, projetos intergeracionais, diversificação da composição sociodemográfica da força de trabalho, integração de competências entre os diversos trabalhadores e equipes, transferência de conhecimento e experiências no trabalho, intercâmbio na sucessão de cargos, valorização das experiências de vida nas diversas fases da vida no trabalho, aspectos sociais e culturais no trabalho, entre outros aspectos que podem envolver a diversidade humana, sobretudo etária, no ambiente organizacional.

\section{CAMINHOS PARA O ESTUDO SOBRE O AGEISMO NAS ORGANIZAÇÕES}

Mesmo havendo um pequeno aumento no número das pesquisas sobre ageismo no campo da Administração, importantes contribuições surgiram até o momento: a reflexão sobre a importância do trabalho no processo de envelhecimento humano e a discussão das causas e consequências do ageismo para o trabalhador (BRITO et al., 2019; LOTH; SILVEIRA, 2014), a elaboração e/ou revalidação de escalas de percepção (FRANÇA et al., 2017; CEPELLOS; TONELLI, 2017; SIQUEIRA-BRITO; FRANÇA; VALENTINI, 2016) e a convocação das 
organizações para o desenvolvimento de práticas de gestão da idade e combate ao ageismo (BRITO et al., 2019; SILVA; HELAL, 2019; CEPELLOS; TONELLI, 2017; LOTH; SILVEIRA, 2014; VASCONCELOS, 2012).

É possível verificar lacunas do conhecimento científico acerca do tema, o que motiva a proposição de novas pesquisas na área, incluindo: estudos interdisciplinares, longitudinais e em diferentes contextos organizacionais, além de estudos que associem outras variáveis ao envelhecimento, como raça, gênero, deficiência, classe social e grau de instrução (LOCATELLI; FONTOURA, 2013; FONTOURA, 2014; LOTH; SILVEIRA, 2014); estudos que incluam a participação dos próprios profissionais mais velhos, estudos quantitativos com representatividade populacional ou pesquisas que verifiquem a influência de outras variáveis, como tamanho da empresa (CEPELLOS, 2013); o estudo do ageismo direcionado a grupos mais jovens nas organizações de trabalho (LOTH; SILVEIRA, 2014); estudos sobre a percepção dos trabalhadores mais jovens em relação aos mais velhos e a identificação de preditores para o ageismo, visando intervenções organizacionais para a sua redução (FRANÇA et al., 2017); estudos sobre práticas de gestão da idade e medidas que reduzam o preconceito por conta da idade (CEPELLOS, 2018); estudos qualitativos a respeito do ageismo bidirecional entre gerações (PAIVA; SOBREIRA; LIMA, 2019).

Para Fontoura e Piccinini (2012), é urgente pensar em como as organizações estão respondendo ao envelhecimento da força de trabalho, visto que esse processo afeta a própria organização e influencia as decisões de trabalhadores, de outras empresas e do governo. Assim, outra oportunidade de pesquisa se desenha frente a necessidade de conceber como os gestores organizacionais percebem e enfrentam o ageismo nas organizações em que atuam.

França et al. (2017) apontam que os gestores são os principais mobilizadores do mercado de trabalho, sendo relevante o desenvolvimento de pesquisas sobre as mudanças de percepção frente ao envelhecimento dos trabalhadores. Para Paiva, Sobreira e Lima (2019), a maneira como os indivíduos são percebidos pode influenciar a compreensão de gestores sobre o assunto e a tomada de decisão nas organizações, influenciando no desempenho de uma empresa e no estilo de vida de seus funcionários. Pelo exposto, a condução das organizações no enfrentamento do preconceito etário será determinante sobre a perpetuação (ou não) das práticas de ageismo no ambiente organizacional.

As pesquisas nacionais apontam diversas possibilidades de futuras pesquisas sobre o estudo do ageismo nas organizações, que estão sintetizadas no Quadro 2. 
Quadro 2 - Sugestões de novos estudos e pesquisas sobre ageismo

\begin{tabular}{|c|c|}
\hline Obra & Sugestões dos autores \\
\hline $\begin{array}{c}\text { Fontoura e } \\
\text { Piccinini }(2012)\end{array}$ & $\begin{array}{l}\text { Estudos sobre como as organizações estão adaptando suas ações de Gestão de } \\
\text { Pessoas (GP) e como essas práticas afetam o trabalho dos mais velhos; } \\
\text { Pesquisa sobre as implicações do envelhecimento nas empresas brasileiras para } \\
\text { subsidiar tanto a criação de políticas públicas quanto as ações de GP nas } \\
\text { organizações. }\end{array}$ \\
\hline Cepellos (2013) & $\begin{array}{l}\text { Pesquisa com os próprios profissionais mais velhos; } \\
\text { Pesquisa quantitativa sobre a influência de outras variáveis como tamanho da } \\
\text { empresa, setor ou origem na adoção das práticas de gestão da idade; } \\
\text { Pesquisa qualitativa em que sejam investigadas questões mais complexas do } \\
\text { envelhecimento nas organizações, seja pelo ponto de vista dos gestores, seja dos } \\
\text { profissionais mais velhos. }\end{array}$ \\
\hline $\begin{array}{c}\text { Locatelli e } \\
\text { Fontoura (2013) }\end{array}$ & $\begin{array}{l}\text { Realizar estudos longitudinais e em diferentes contextos de trabalho, especialmente } \\
\text { que se originem de grupos de pesquisa em Administração; } \\
\text { Discutir o tema sob a perspectiva das próprias pessoas idosas; } \\
\text { Estudar o processo de envelhecimento considerando a sua complexidade e } \\
\text { heterogeneidade, além das especificidades e singularidades desse grupo geracional no } \\
\text { universo organizacional; } \\
\text { Analisar a empregabilidade de adultos acima dos } 60 \text { anos, tanto aposentados quanto } \\
\text { não aposentados; } \\
\text { Realizar estudos organizacionais que visem aliar o envelhecimento a outras variáveis } \\
\text { como raça, gênero, deficiência, classe social e grau de instrução. }\end{array}$ \\
\hline Fontoura (2014) & $\begin{array}{l}\text { Estudos que relacionem envelhecimento no trabalho a outras variáveis como raça, } \\
\text { classe social, grau de instrução e presença de deficiência; } \\
\text { Ampliar as abordagens qualitativas e quantitativas adotando outras técnicas de coleta } \\
\text { de dados, como survey e grupos focais; } \\
\text { Repetir o estudo a cada cinco anos, a fim de monitorar as alterações e promover } \\
\text { ações práticas e políticas públicas em favor dos trabalhadores mais velhos nas } \\
\text { organizações. }\end{array}$ \\
\hline $\begin{array}{l}\text { Loth e Silveira } \\
\qquad(2014)\end{array}$ & $\begin{array}{l}\text { Desenvolver estudos que agreguem a interseccionalidade de gênero, classe social e } \\
\text { também raça ao fenômeno do etarismo [ageismo] e de } \\
\text { seus estereótipos; } \\
\text { Investigar o fenômeno do etarismo direcionado a grupos de jovens nas organizações; } \\
\text { Investigar o fenômeno do etarismo considerando a ótica das pessoas mais jovens. }\end{array}$ \\
\hline $\begin{array}{l}\text { Siqueira-Brito, } \\
\text { França e Valentini } \\
\qquad(2016)\end{array}$ & $\begin{array}{l}\text { Ampliar o conhecimento sobre o constructo ageismo no contexto organizacional } \\
\text { utilizando a Escala de Ageismo no Contexto Organizacional (EACO) elaborada pelos } \\
\text { autores e/ou associando-a a outras escalas que investiguem as causas e consequências } \\
\text { do ageismo no mundo do trabalho. }\end{array}$ \\
\hline $\begin{array}{l}\text { França et al. } \\
\text { (2017) }\end{array}$ & $\begin{array}{l}\text { Investigações sobre as percepções dos trabalhadores mais jovens, que são os } \\
\text { expectadores daqueles que estão deixando a organização; } \\
\text { Estudos que adotem a EACO no seu formato original, com possíveis acréscimos de } \\
\text { outros estudiosos; } \\
\text { Estudos que repliquem a EACO a nível nacional ou transnacional; } \\
\text { Pesquisas que identifiquem preditores para o ageismo e que tracem formas de } \\
\text { intervenção organizacional para a sua redução. }\end{array}$ \\
\hline Aquino (2018) & $\begin{array}{l}\text { Compreender as idiossincrasias das gerações, suas diferenças e particularidades, } \\
\text { alinhadas ao conhecimento das políticas públicas a respeito do idoso e, também, os } \\
\text { estudos de previsibilidade de oferta de mão de obra; } \\
\text { Analisar e compreender os diferentes perfis geracionais, suas demandas e } \\
\text { motivações, para estabelecer políticas de gestão que favoreçam a troca geracional e } \\
\text { consequentes benefícios para os resultados organizacionais. }\end{array}$ \\
\hline Cepellos (2018) & $\begin{array}{l}\text { Investigar os efeitos pessoais e profissionais do preconceito pela idade para os } \\
\text { profissionais maduros; } \\
\text { Realizar estudos comparativos para identificar o sentido do trabalho do profissional } \\
\text { maduro brasileiro em relação a profissionais de outras culturas, como também acerca } \\
\text { da aceitação do profissional idoso nas organizações; } \\
\text { Averiguar a adoção de práticas de gestão de idade, como se deu o processo de } \\
\text { implementação, quais os principais desafios enfrentados, qual a percepção de }\end{array}$ \\
\hline
\end{tabular}




\begin{tabular}{|c|l|}
\hline & $\begin{array}{l}\text { profissionais maduros com relação às condições de trabalho, os pontos forte e } \\
\text { sugestões de melhoria. }\end{array}$ \\
\hline Brito et al. (2019) & $\begin{array}{l}\text { Formular de diretrizes que ajudem a combater e prevenir esse tipo de discriminação, } \\
\text { incluindo instituições, políticas públicas, relações sociais e as próprias pessoas } \\
\text { idosas. }\end{array}$ \\
\hline $\begin{array}{c}\text { Paiva, Sobreira e } \\
\text { Lima (2019) }\end{array}$ & $\begin{array}{l}\text { Usar um instrumento de pesquisa de cunho qualitativo capaz de entender mais } \\
\text { profundamente a distorção existente na percepção individual de ageismo. }\end{array}$ \\
\hline $\begin{array}{c}\text { Silva e Helal } \\
(2019)\end{array}$ & $\begin{array}{l}\text { Pesquisar o fenômeno ageismo de modo mais aprofundado, e não apenas a partir da } \\
\text { aplicação de escalas de percepção. }\end{array}$ \\
\hline
\end{tabular}

Fonte: elaborado pelos autores.

Ao longo dos anos, os pesquisadores sobre envelhecimento e ageismo nos estudos organizacionais têm identificado diversas lacunas no conhecimento que podem ser preenchidas por diversos tipos de pesquisas. Atualmente, não é possível apontar um padrão de estudos sobre o assunto, embora se destaquem os trabalhos estritamente teóricos, o que reforça a necessidade de realização de pesquisas empíricas para que dialoguem com a teoria produzida. Neste sentido, há possibilidades que incluem pesquisas quantitativas e qualitativas, pesquisas incluindo trabalhadores em todas as faixas etárias, estudos que incluam outras variáveis além da idade (tanto variáveis inerentes ao sujeito quanto ao contexto organizacional), pesquisas longitudinais, transversais e transculturais, pesquisas com a adoção de escalas de avaliação e pesquisas que envolvem a atuação dos gestores.

É visível que ainda há muito conhecimento a se produzir acerca do preconceito etário no contexto organizacional, reconhecendo que esse é um tema que influencia os trabalhadores, as organizações e a sociedade como um todo. Sendo assim, espera-se que os dados consolidados no Quadro 2 possam inspirar e motivar outros estudiosos a investigarem o tema.

\section{CONSIDERAÇÕES FINAIS}

O preconceito em virtude da idade é um fenômeno crescente nos estudos organizacionais, visto que o envelhecimento da população e, consequentemente, da força de trabalho, instigam pesquisadores a direcionar esforços para a sua investigação. Ao longo deste trabalho foram levantadas algumas considerações teóricas acerca do ageismo, as principais consequências da sua prática e estratégias de enfrentamento no contexto organizacional.

Costumeiramente são identificadas consequências do ageismo sobre o trabalhador, destacando-se, entre outras, a exclusão do processo de contratação e treinamentos, perda da identidade e insatisfação com o trabalho. Nota-se que os estudos não direcionam esforços para verificar em que medidas tais consequências refletem o desempenho do trabalhador e da 
organização, logo, a ausência de pesquisas sobre a problemática impede, por exemplo, a identificação das maneiras como a prática ageista afeta o desempenho organizacional.

No berço das proposituras de estratégias de mitigação do ageismo, os pesquisadores têm valorizado a formação de equipes intergeracionais nas organizações, convocando gestores a pensarem práticas organizacionais pautadas no respeito à diversidade e equidade. Porém, a maioria desses estudos é baseada em discussões teóricas e, em casos isolados, em pesquisas empíricas ainda incipientes; há, inclusive, uma ausência de informações sobre como é possível formar essas equipes e quais caminhos percorrer com elas. Logo, apenas a formação de equipes pode não ser suficiente para a mitigação do preconceito em virtude da idade.

Sendo assim, esse artigo reforça que a mitigação do ageismo nas organizações deve ocorrer através da adoção de estratégias que vão além da formação de equipes intergeracionais, incluindo, paralelamente, outras ações de inserção e permanência de trabalhadores nas diversas faixas etárias, sobretudo os mais velhos, como políticas de contratação desses trabalhadores, qualificação profissional, flexibilização das condições de trabalho, sensibilização e conscientização dos trabalhadores mais jovens acerca dos estereótipos etários, gerenciamento das equipes intergeracionais e aproveitamento de mão de obra qualificada.

Dada a complexidade desse fenômeno, verifica-se inúmeras lacunas ainda a serem preenchidas por parte dos pesquisadores sobre o tema, o que pode promover a ampliação dos estudos no país. Nesse cenário, os estudiosos apontam algumas propostas de pesquisa, como estudos interdisciplinares, longitudinais e em diferentes contextos organizacionais, estudos que incluam outras variáveis como raça, gênero, deficiência e classe social, estudos que incluam a participação dos diferentes grupos etários e estudos sobre o ageismo direcionado aos mais jovens.

Este trabalho é limitado em função da sua natureza estritamente teórica, no entanto, espera-se que as discussões trazidas ofereçam melhor entendimento sobre as multifaces do preconceito etário nas organizações e possibilitem pensar outras estratégias para além da formação das equipes intergeracionais. Além disso, estima-se que ele motive ao desenvolvimento de pesquisas empíricas sobre as reflexões realizadas.

Do ponto de vista teórico, o artigo contribui para problematizar a aplicabilidade do conceito de gerações frente ao ageismo e, apesar da importância de se discutir a intergeracionalidade no ambiente de trabalho, não se pode perder de vista a heterogeneidade da força de trabalho, que é marcada por inúmeros elementos além da idade cronológica. Do ponto de vista prático, espera-se que o artigo possa incentivar a discussão sobre o tema entre trabalhadores e estimular a implementação de práticas para a mitigação do ageismo. 


\section{REFERÊNCIAS}

AQUINO, Fernanda A. Z. O. Longevidade e gestão de pessoas: as relações de trabalho nas organizações. Dissertação (Mestrado em Desenvolvimento Humano) - Universidade de Taubaté, São Paulo, 2018. Disponível em: <https://mpemdh.unitau.br/wpcontent/uploads/2016/dissertacoes/mdh/Fernanda-Aparecida-Zanin-de-Oliveira-Aquino.pdf $>$. Acesso em: 08 mai. 2020.

BALTES, Paul B. Theoretical propositions of the lifespan developmental psychology: on the dynamics between growth and decline. Developmental Psychology, v. 23, n. 5, pp. 611-26, 1987. DOI: https://doi.org/10.1037/0012-1649.23.5.611

BECTON, John B.; WALKER, Harvell J.; JONES-FARMER, Allison. Generational differences in workplace behavior. Journal of Applied Social Psychology, v. 44, n. 3, pp. 175-89, 2014. DOI: https://doi.org/10.1111/jasp.12208

BOURRY, Elaine C. M. S.; OLIVEIRA, Lúcia B. Transição de Carreira após a Demissão: Uma Pesquisa com Trabalhadores na Maturidade. Anais do XLI Encontro da Anpad. São Paulo, 2017. Disponível em:

$<$ http://www.anpad.org.br/eventos.php?cod_evento=1\&cod_evento_edicao=96\&cod_edicao_ subsecao=1665>. Acesso em: 07 fev. 2020.

BRITO, Vitória F.; SILVA, Jônatas K. O.; MOURA, Júlia T. S.; RIBEIRO, Maria C. C.; SILVA, Josevânea. Trabalho e envelhecimento: uma análise do ageismo no contexto organizacional. Anais do VI Congresso Internacional de Envelhecimento Humano, Campina Grande: 26 a 28 de junho, 2019. Disponível em:

<https://editorarealize.com.br/revistas/cieh/trabalhos/TRABALHO_EV125_MD1_SA13_ID1 215_27052019160253.pdf >. Acesso em 20 de agosto de 2019.

BUTLER, Robert N. Age-ism: Another form of bigtory. The Gerontologist, vol. 9, 1969, pp. 243-6. DOI: https://doi.org/10.1093/geront/9.4 Part 1.243

Ageism: a foreword. Journal of Social Issues, v. 36, n. 2, pp. 8-11, 1980. DOI:

https://doi.org/10.1111/j.1540-4560.1980.tb02018.x

CARVALHO, Alessandra S. Gestão de Pessoas e Envelhecimento: Sentido do Trabalho para o Idoso. Anais do XXXIII Encontro da Anpad, São Paulo: 19 a 23 de setembro, 2009. Disponível em: <http://www.anpad.org.br/admin/pdf/GPR3213.pdf>. Acesso: 11 fev. 2020.

CEPELLOS, Vanessa M. Envelhecimento nas organizações: os grandes debates sobre o tema nos estudos de Administração de Empresas. Teoria e Prática em Administração, v. 8, n. 1, pp. 138-59, 2018. DOI: http://dx.doi.org/10.21714/2238-104X2018v8i1-37614

O envelhecimento nas organizações: das percepções de gestores de Recursos Humanos às práticas de gestão da idade. 98f. Dissertação (mestrado) - Escola de Administração de Empresas de São Paulo, Fundação Getúlio Vargas, São Paulo, 2013. Disponível em: <https://bibliotecadigital.fgv.br/dspace/handle/10438/10588>. Acesso em: 09 abr. 2020. 
CEPELLOS, Vanessa M.; TONELLI, Maria J. Envelhecimento profissional: percepções e práticas de gestão da idade. Revista Alcance, v. 24, n. 1, pp. 4-21, 2017.

DOI: http://dx.doi.org/10.14210/alcance.v24n1.p004-021

CLARK, Robert L.; OGAWA, Naohiro. Human Resources Policies and Older Works in Japan. The Gerontologist, v. 36, n. 5, 1996, p. 627-36. DOI:

https://doi.org/10.1093/geront/36.5.627

DRUMOND, Thais D. R.; ITUASSU, Cristina T.; SILVA, Wanderleia V.; LAVINAS, Marina R. Geração Y ou Gerações Y? Concordâncias e controvérsias na literatura científica nacional sobre quem são esses profissionais. Anais do XLIV Encontro Nacional da Anpad, on-line: 14 a 16 de outubro, 2020. Disponível em:

<http://www.anpad.org.br/admin/pdf/2020_EnANPAD_GPR2376.pdf $>$. Acesso em: 19 fev. 2021.

FONTOURA, Daniele S. Envelhecimento e mercado de trabalho no setor hoteleiro brasileiro e português: uma perspectiva de gênero. Tese (Doutorado em Administração) Universidade Federal do Rio Grande do Sul / Universidade de Lisboa, Porto Alegre / Lisboa, 2014. Disponível em:

$<$ https://www.lume.ufrgs.br/bitstream/handle/10183/107269/000945353.pdf?sequence=1\&is Allowed $=\mathrm{y}>$. Acesso em: 08 mai. 2020.

FONTOURA, Daniele S.; PICCININI, Valmiria C. Envelhecimento populacional e gestão de pessoas: pesquisas internacionais e notas para o Brasil. Anais do XXXVI Encontro da Anpad, Rio de Janeiro: 22 a 26 de setembro, 2012. Disponível em:

<http://www.anpad.org.br/admin/pdf/2012_GPR2116.pdf>. Acesso em: 05 dez. 2019.

FRANÇA, Lucia H. F. P.; SIQUEIRA-BRITO, Andreia R.; VALENTINI, Felipe;

VASQUES-MENEZES, Ione; TORRES, Claudio V. Ageismo no contexto organizacional: a percepção de trabalhadores brasileiros. Rev. Bras. Geriatria e Gerontologia, Rio de Janeiro, v. 20, n. 6, pp. 765-77, 2017. DOI: https://doi.org/10.1590/1981-22562017020.170052

GOLDANI, Ana Maria. Desafios do "preconceito etário" no Brasil. Educ. Soc., Campinas, v. 31, n. 111, pp. 411-34, 2010. DOI: https://doi.org/10.1590/S0101-73302010000200007

GOMES, Jorge F. S.; RODRIGUES, Ana F.; VELOSO, Ana. Regresso às Origens: A Importância do Indivíduo na Criatividade nas Organizações. RAC, Rio de Janeiro, v. 20, n. 5, pp. 568-89, 2016. DOI: http://dx.doi.org/10.1590/1982-7849rac2016150096

GONÇALVES, Bianca A. G.; FERREIRA, Marcela E. Gerações e suas influências dentro das organizações. Revista Maiêutica, Indaial, v. 4, n. 1, pp. 47-56, 2016. Disponível em: 〈https://publicacao.uniasselvi.com.br/index.php/GESTAO_EaD/article/view/1595/724>.

Acesso em: 26 nov. 2019.

GROISMAN, Daniel. A velhice, entre o normal e o patológico. História, Ciências, Saúde Manguinhos, Rio de Janeiro, v. 9, n. 1, pp. 61-78, 2002. DOI: https://doi.org/10.1590/S0104$\underline{59702002000100004}$ 
HELAL, Diogo; SILVA, Romário A. Ageismo nas organizações: um estudo em uma rede de distribuição de autopeças na Região Nordeste. Anais do XXII Seminários em

Administração (Semead), nov. 2019. Disponível em:

$\langle$ http://login.semead.com.br/22semead/anais/resumo.php?cod_trabalho=364>. Acesso: 11 fev. 2020.

HELAL, Diogo; NÓBREGA, Cléverson; LIMA, Tatiana. Reflexões sobre a aposentadoria: perspectivas e desafios para os trabalhadores e paga a gestão de pessoas. Anais do VI

Encontro de Gestão de Pessoas e Relações de Trabalho da Anpad, Curitiba: 28 a 30 de maio, 2017. Disponível em:

$<$ http://www.anpad.org.br/eventos.php?cod_evento=16\&cod_evento_edicao=88\&cod_edicao subsecao $=1425 \&$ cod edicao trabalho=22351 > . Acesso em: 06 abr. 2020.

IBGE. Instituto Brasileiro de Geografia e Estatística. Projeção da população do Brasil por sexo e idade para o período 2000/2060. Nota técnica. Rio de Janeiro: 2018. Disponível em: <https://www.ibge.gov.br/estatisticas/sociais/populacao/9109-projecao-dapopulacao.html?=\&t=downloads $>$. Acesso em: 20 ago. 2019.

IWEINS, Caroline; DESMETTE, Donatienne; YZERBYT, Vincent; STINGLHAMBER, Florence. Ageism at work: The impact of intergenerational contact and organizational multiage perspective. European Journal of Work and Organizational Psychology, 2013. DOI: http://dx.doi.org/10.1080/1359432X.2012.748656

IWEINS, Caroline; DESMETTE, Donatienne; YZERBYT, Vincent. Ageism at work: what happens to older workers who benefit from prefential treatment? Psychologica Belgica, v. 52, n. 4, pp. 327-49, 2012. DOI: http://dx.doi.org/10.5334/pb-52-4-327

KEEL, Jessica M.; SAUTER, Steven L.; HANSEMAN, Dennis J. A idade e o stress no trabalho: o que sabemos? In: ROSSI et al. (org.). Stress e Qualidade de Vida no Trabalho. São Paulo: Atlas, 2009.

LEVY, Sheri R.; MACDONALD, Jamie L. Progress on understanding ageism. Journal of Social Issues, v. 72, n. 1, pp. 5-25, 2016. DOI: https://doi.org/10.1111/josi.12153

LIMA, Thales B.; HELAL, Diogo H. Trabalho na terceira idade: uma revisão sistemática da literatura brasileira entre 2008 e 2012. Gestão e Sociedade, v. 7, n. 18, pp. 369-94, 2013. DOI: https://doi.org/10.21171/ges.v7i18.1914

LOCATELLI, Patrícia A. P. C.; FONTOURA, Daniele S. Envelhecimento populacional e os estudos em Administração. Revista Gestão e Sociedade, Belo Horizonte, v. 7, n. 17, pp. 273300, 2013. DOI: https://doi.org/10.21171/ges.v7i17.1689

LOTH, Guilherme B.; SILVEIRA, Nereida. Etarismo nas organizações: um estudo dos estereótipos em trabalhadores envelhecentes. Revista de Ciências da Administração, v. 16, n. 39, p. 65-82, 2014. DOI: https://doi.org/10.5007/2175-8077.2014v16n39p65

MALATEST, Robert. A. The Aging Workforce and Human Resources Development Implications For Sector Councils. Ottawa: Malatest \& Associates Ltd., 2003. 
MARQUEZE, Elaine C.; MORENO, Claudia R. C. Satisfação no trabalho - uma breve revisão. Revista Brasileira de Saúde Ocupacional, São Paulo, v. 30, n. 112, pp. 69-79, 2005. DOI: https://doi.org/10.1590/S0303-76572005000200007

MARTINEZ, Maria C.; PARAGUAY, Ana Isabel B. B.; LATORRE, Maria do Rosário D. O. Relação entre satisfação com aspectos psicossociais e saúde dos trabalhadores. Rev Saúde Pública, v. 38, n. 1, pp. 55-61, 2004. DOI: https://doi.org/10.1590/S0034$\underline{89102004000100008}$

MCGREGOR, Judy; GRAY, Lance. Stereotypes and older workers: the New Zealand experience. Social policy jornal of New Zealand, n. 18, pp. 163-77, 2002. Disponível em: $<$ https://www.msd.govt.nz/documents/about-msd-and-our-work/publicationsresources/journals-and-magazines/social-policy-journal/spj18/18-pages163-177.pdf >. Acesso em: 25 out. 2019.

MILHOME, Jaqueline C.; ROWE, Diva E. O. Gerações Brasileiras: uma proposta de classificações a partir de eventos históricos marcantes. Anais do XLIV Encontro Nacional da Anpad, on-line: 14 a 16 de outubro, 2020. Disponível em: $<$ http://www.anpad.org.br/admin/pdf/2020 EnANPAD GPR3003.pdf>. Acesso em: 19 fev. 2021.

NELSON, Todd D. Ageism: The Strange Case of Prejudice Against the Older You. In: WIENER, R. L.; WILLBORN, S. L. (eds.). Disability and Aging Discrimination, Springer, New York, pp. 37-47, 2011. DOI: https://doi.org/10.1007/978-1-4419-6293-5

NERI, Anita L. O legado de Paul B. Baltes à Psicologia do Desenvolvimento e do Envelhecimento. Temas em Psicologia, v. 14, n. 1, pp. 17-34, 2006. Disponível em: <http://pepsic.bvsalud.org/pdf/tp/v14n1/v14n1a05.pdf >. Acesso em: 05 dez. 2019.

PAIVA, Nícolas M. F.; SOBREIRA, Érica M. C.; LIMA, Tereza C. B. Que clima é esse? Ageísmo e Relações Intergeracionais em uma Organização do Setor Público. Anais do X Encontro de Estudos Organizacionais da Anpad, Fortaleza: 16 a 18 de maio, 2019. Disponível em: <http://www.anpad.org.br/eventos.php?cod_evento=4\&cod_evento_edicao=95\&cod_edicao_ subsecao=1649\&cod edicao trabalho=25809 > . Acesso em: 06 fev. 2020.

PAOLINI, Karoline S. Desafio da inclusão do idoso no mercado de trabalho. Revista Brasileira de Medicina do Trabalho, v. 14, n. 2, pp. 177-82, 2016. Disponível em $<$ http://www.rbmt.org.br/details/47/pt-BR/desafios-da-inclusao-do-idoso-no-mercado-detrabalho>. Acesso: 07 fev. 2020.

PERES, Marcos A. C. As estratégias empresariais e a exclusão por idade. Revista Gerenciais, v. 2, n. 1, 2003. Disponível em: <http://www.spell.org.br/documentos/ver/26658/as-estrategias-empresariais-e-a-exclusaopor-idade>. Acesso em: 08 mai. 2020.

SCHNEIDER, Rodolfo H.; IRIGARAY, Tatiana Q. O envelhecimento na atualidade: aspectos cronológicos, biológicos, psicológicos e sociais. Estudos de Psicologia, Campinas, v. 25, n. 4, pp. 585-93, 2008. DOI: https://doi.org/10.1590/S0103-166X2008000400013 
SILVA, Romário A.; HELAL, Diogo H. Ageismo nas Organizações: Questões para Debate. Revista de Administração IMED, Passo Fundo, v. 9, n. 1, p. 187-97, 2019. DOI: https://doi.org/10.18256/2237-7956.2019.v9i1.3167

SILVA, Rodrigo C.; DUTRA, Joel S.; VELOSO, Elsa F. R.; TREVISAN, Leonardo N. As gerações em distintos contextos organizacionais. Gestão \& Regionalidade, v. 30, n. 89, 2014. DOI: https://doi.org/10.13037/gr.vol30n89.2798

SIQUEIRA-BRITO, Andreia da R.; FRANÇA, Lucia H. F. P.; VALENTINI, Felipe. Análise Fatorial Confirmatória da escala de ageismo nas organizações. Avaliação Psicológica, v. 15, n. 3, pp. 333-45, 2016. DOI: http://dx.doi.org/10.15689/ap.2016.1503.06

TEIXEIRA, Selena M. O.; SOUZA, Luana E. C.; MAIA, Luciana M. Ageismo institucionalizado: uma revisão teórica. Revista Kairós-Gerontologia, São Paulo, v. 21, n. 3, pp. 129-49, 2018. DOI: https://doi.org/10.23925/2176-901X.2018v21i3p129-149

VASCONCELOS, Anselmo F. Ageism: a study of demographic diversity in Brazil. Management Research: The Journal of the Iberoamerican Academy of Management, v. 10, n. 3, pp. 187-207, 2012. DOI: https://doi.org/10.1108/1536-541211273865

VIEIRA, Rodrigo S. S.; LIMA, Marcus E. O. Estereótipos sobre os idosos: dissociação entre crenças pessoais e coletivas. Temas em Psicologia, v. 25, n. 4, pp. 947-58, 2015. DOI:

http://dx.doi.org/10.9788/TP2015.4-11 